\title{
Two unusual cases of autologous HSCT related TMA with kidney injury
}

\author{
Xingtong Dong ${ }^{1}$, Qiang Jia ${ }^{1}$, Wenjing $\mathrm{Fu}^{1}$, Yinping $\mathrm{Li}^{1}$, Na Lin ${ }^{1}$, Wen Li, Wei Ye ${ }^{2}$, Yubing Wen ${ }^{2}$, \\ Aihua Zhang ${ }^{1}$ \\ ${ }^{1}$ Department of Nephrology, Xuanwu Hospital, Capital Medical University, Beijing, China; ${ }^{2}$ Department of Nephrology, Peking Union Medical \\ College, Beijing, China \\ Correspondence to: Dr. Aihua Zhang. Department of Nephrology, Xuanwu Hospital, Capital Medical University, Changchun Street 45\#, Xicheng \\ District, Beijing 100053, China. Email: zhangaihua0982@sina.com.
}

\begin{abstract}
Kidney injury caused by transplant-associated thrombotic microangiopathy (TA-TMA) in patients who underwent allogeneic hematopoietic stem cell transplantation (allo HSCT) is relatively frequent. However, it is rarely reported in patients undergoing autologous HSCT (aHSCT). There are a few studies reported that TA-TMA could occur in pediatric patients undergoing aHSCT, but the condition in adult patients is rarely described. Furthermore, almost all the patients who suffered from TA-TMA developed typical and severe manifestations which should be treated with aggressive target therapy. Nevertheless, we presented two cases of kidney injury caused by TA-TMA after aHSCT with specific clinical features. Case 1, a 33-year-old Chinese male diagnosed with Hodgkin's lymphoma developed TA-TMA -associated kidney injury 4 months after transplantation. Case 2, a 49-year-old Chinese female with central nervous lymphoma developed TA-TMA-related kidney injury 3 months after transplantation. Both patients presented "mild" and atypical features of TA-TMA and their kidney function was managed effectively with low-dose prednisone therapy. TA-TMA related kidney injury can occur in patients who underwent aHSCT. Patients with TA-TMA could develop atypically "mild" features. Low-dose prednisone may be effective in place of routine eculizumab treatment regimen. We recommend that clinicians prompt an investigation for TA-TMA in patients presenting kidney injury in the background of aHSCT to facilitate early diagnosis.
\end{abstract}

Keywordsı Kidney injury; transplant; autologous transplant-associated thrombotic microangiopathy; case report

Submitted Jan 27, 2021. Accepted for publication May 25, 2021.

doi: 10.21037/apm-21-226

View this article at: https://dx.doi.org/10.21037/apm-21-226

\section{Introduction}

Kidney injury is a common complication of hematopoietic stem cell transplantation (HSCT). Among factors that can cause kidney injury, transplant-associated thrombotic microangiopathy (TA-TMA) is well-recognized and characterized by thrombocytopenia, nonimmune hemolytic anemia, peripheral blood schistocytes and multiple organ damage including kidney dysfunction (1). The pathological mechanism of TA-TMA is endothelial injury caused by a variety of risk factors including gender, genetics (inherent), preconditioning regimen, use of human leukocyte antigen (HLA)-mismatched donors (transplant related); receipt of calcineurin inhibitors, development of graft- $v s$. -hostdisease, or certain infections (post-transplant related). However, compare with patients who underwent allogeneic hematopoietic stem cell transplantation (alloHSCT), the incidence of TA-TMA is far less in patients who underwent autologous hematopoietic stem cell transplantation (aHSCT). Previous cases reported so far are pediatric aHSCT recipients presenting typical and severe clinical manifestations of TA-TMA and treated with TMA targeting therapy such as eculizumab $(2,3)$. In the present report, we attempt to fill this gap in the literature. We described two adult aHSCT recipients who developed kidney injury with atypical features of TMA and responded well to low-dose 
prednisone therapy to enhance timely screenings for TATMA. We present the following cases in accordance with the CARE reporting checklist (available at https://apm. amegroups.com/article/view/10.21037/apm-21-226/rc).

\section{Case presentation}

\section{Case 1}

A 33-year-old Chinese male with nodular sclerosis Hodgkin's lymphoma (NSHL) underwent autologous transplantation following myeloablative conditioning with BEAC (BCNU, etoposide, Ara-C, cyclophosphamide). Four months after transplantation, he presented with foamy urine. Urinalysis was positive for protein $(++)$, and red blood cell ( 6 per high power field) and urinary protein excretion was $2.05 \mathrm{~g}$ per 24 hours. A full blood count revealed $90 \mathrm{~g} / \mathrm{L}$ hemoglobin $(\mathrm{HB})$ and $60 \times 10^{9} / \mathrm{L}$ platelet (PLT). Elevations in lactate dehydrogenase (LDH) (484 IU/L) and serum creatinine (Scr) $(88 \mu \mathrm{mol} / \mathrm{L})$ were detected in subsequent tests. No edema, oliguria or gross hematuria was noted. Bone marrow biopsy result showed normal. Complete remission has been achieved as per hematologist review. The patient was admitted to our renal ward on the 5 th month after transplantation with an elevated serum creatinine (sCr) level of $120 \mu \mathrm{mol} / \mathrm{L}$. Except for mild blood pressure elevation, physical assessments on admission were unremarkable. Irbesartan (Angiotensin II receptor blocker) $150 \mathrm{mg}$ once daily was ordered with good therapeutic effect. Given the damaged renal function and deranged hematological parameters, patient was tested for anti-nuclear antibodies (ANA), anti-neutrophil cytoplastic antibodies (ANCA) and antiphospholipid antibodies (aPL) to rule out the possibility of autoimmune diseases. All his antibody screenings were found negative (Table 1). Surprisingly, his HB, LDH and PLT improved significantly (Table 1) and 24-hour urinary protein excretion decreased to $0.54 \mathrm{~g}$ without any other therapy except ARB, although his serum creatinine level remained high at approx. $120 \mu \mathrm{mol} / \mathrm{L}$. To uncover this phenomenon, kidney biopsy was performed. In kidney biopsy, diffuse proliferation of mesangial cells and endothelial cells, segmental thickening of glomerular base membrane (GBM) with mesangial interposition and double contour of the GBM were showed up in the light microscope (LM) image (Figure 1). Furthermore, Coombs test (-), ADAMTS13 activity (-) and peripheral smear (schistocytes $\geq 2$ per high power field) were completed and all these clinical findings fulfilled criteria for the diagnosis of TMA. Early discharge with irbesartan (150mg once daily) was made on the ground of the stable renal function as well as patient's refusal of further medical treatment. His followup results during four-month outpatient visits revealed fluctuations in the levels of HB (97-121 g/L) and PLT $\left(120 \times 10^{9} / \mathrm{L}-221 \times 10^{9} / \mathrm{L}\right)$. LDH was within normal range. 24-hour urinary protein excretion gradually decreased to $0.24 \mathrm{~g}$. The patient was re-admitted with a rising $\mathrm{sCr}$ of $150 \mu \mathrm{mol} / \mathrm{L}$. Prednisone $15 \mathrm{mg}$ once daily was commenced after patient consent was obtained. The patient showed a good response to prednisone therapy in 2 weeks' time $-\mathrm{sCr}$ dropped to $112 \mu \mathrm{mol} / \mathrm{L}$ and HB elevated to $120 \mathrm{~g} / \mathrm{L}$. The patient was then discharged and treated in our outpatient setting.

\section{Case 2}

A 49-year-old Chinese female, who was diagnosed of primary central nervous system diffuse large $B$ cell lymphoma (PCNS-DLBCL) and has undergone autologous transplantation following myeloablative conditioning with BEAC regimen (BCNU, etoposide, Ara-C, cyclophosphamide), was referred to our clinic with complaints of foamy urine and facial edema 4 months after transplantation. She has a past medical history of hypertension and her blood pressure was well managed. In laboratory tests, $\mathrm{HB}, \mathrm{PLT}, \mathrm{LDH}$ and $\mathrm{sCr}$ were $100 \mathrm{~g} / \mathrm{L}, 100 \times 10^{9} / \mathrm{L}, 347 \mathrm{IU} / \mathrm{L}$, and $53 \mu \mathrm{mol} / \mathrm{L}$, respectively. Microscopic examination revealed RBC (red blood cell) 12/HPF (high power field). 24-hour urinary protein excretion was $3.25 \mathrm{~g}$. Her PLT count continued to drop significantly to $69 \times 10^{9} / / \mathrm{L}$ within a short period of time. She was then admitted to our renal ward. The results of routine laboratory tests including ANA, anti-ANCA, aPL etc. did not support a diagnosis of an autoimmune disease (Table 2). Remarkably, a normalized PLT count was seen without treatment. Irbesartan at a dose of $75 \mathrm{mg}$ per day was started for proteinuria. However, it was therefore advisable to withhold the kidney biopsy due to acute onsets of seizures. Symptomatic epilepsy was diagnosed by neurologist and anti-epileptic medications were commenced. During the following 2 months' followup, her LDH and PLT levels returned to normal range, and urinary protein excretion decreased to $0.92 \mathrm{~g} / 24 \mathrm{~h}$. However, a decline in her HB level (drop to $76 \mathrm{~g} / \mathrm{L}$ ) was noticed associated with an increase in sCr level (103 to $158 \mu \mathrm{mol} / \mathrm{L})$. The patient, at her 6th month post transplantation, was admitted to our renal ward for a kidney biopsy. LM showed diffuse proliferation of endothelial 
Table 1 Case 1 patient's lab test parameters

\begin{tabular}{|c|c|c|c|c|c|c|c|c|c|c|c|c|c|}
\hline Test & $\begin{array}{l}2019 / \\
05 / 06\end{array}$ & $\begin{array}{l}2019 / \\
06 / 04\end{array}$ & $\begin{array}{l}2019 / \\
06 / 11\end{array}$ & $\begin{array}{l}2019 / \\
06 / 30\end{array}$ & $\begin{array}{l}2019 / \\
07 / 04\end{array}$ & $\begin{array}{l}2019 / \\
08 / 19\end{array}$ & $\begin{array}{l}2019 / \\
09 / 26\end{array}$ & $\begin{array}{l}2019 / \\
09 / 30\end{array}$ & $\begin{array}{l}2019 / \\
11 / 05\end{array}$ & $\begin{array}{l}2019 / \\
11 / 07\end{array}$ & $\begin{array}{l}2019 / \\
11 / 13\end{array}$ & $\begin{array}{l}2019 / \\
11 / 21\end{array}$ & $\begin{array}{l}2019 / \\
11 / 27\end{array}$ \\
\hline LDH (IU/L) & 484 & & & 282 & & & 181 & & 197 & & & 226 & \\
\hline Platelet counts $\left(10^{9} / \mathrm{L}\right)$ & 60 & 116 & 100 & 109 & 120 & & 221 & & 211 & 246 & & & 235 \\
\hline Serum creatinine $(\mu \mathrm{mol} / \mathrm{L})$ & 88 & 120 & 117 & 126 & 110 & 110 & 156 & 137 & 154 & & 154 & 132 & 112 \\
\hline C3 (normal) & & & & & & & & & & & & & \\
\hline C4 (normal) & & & & & & & & & & & & & \\
\hline $\begin{array}{l}\text { Renal biopsy pathology } \\
\text { (TMA changes) }\end{array}$ & & & & & & & & & & & & & \\
\hline $\begin{array}{l}\text { ANA (negative) } \\
\text { dsDNA } \\
\text { (negative) }\end{array}$ & & & & & & & & & & & & & \\
\hline Anti-Sm (negative) & & & & & & & & & & & & & \\
\hline Coombs test (negative) & & & & & & & & & & & & & \\
\hline $\begin{array}{l}\text { Adamts } 13 \text { activity } \\
\text { (normal) }\end{array}$ & & & & & & & & & & & & & \\
\hline $\begin{array}{l}\text { Anti-beta2 } \\
\text { glycoprotein (negative) }\end{array}$ & & & & & & & & & & & & & \\
\hline
\end{tabular}

LDH, lactate dehydrogenase; TMA, thrombotic microangiopathy; ANA, anti-nuclear antibodies; ANCA, anti-neutrophil cytoplastic antibodies.

cells, thickened inner aspect of GBM and double contour of the GBM (Figure 2). IF was found negative. EM confirmed the findings of thickened inner loose layer of GBM and swollen endothelial cells (Figure 2). Furthermore, we also did Coombs test, ADAMTS13 activity and antiFactor $\mathrm{H}$ antibody, anti-Factor I antibody tests for her which didn't show any abnormality. The peripheral smear showed schistocytes $\geq 2 / \mathrm{HPF}$, therefore TMA was diagnosed (Table 2). Steroid therapy (prednisone $15 \mathrm{mg}$ once daily) was started as $\mathrm{HB}$ notably decreased to $69 \mathrm{~g} / \mathrm{L}$ and was tapered to $12.5 \mathrm{mg} /$ day when her clinical condition has improved by the $3 \mathrm{rd}$ month of hospitalization $(\mathrm{sCr} 117 \mu \mathrm{mol} / \mathrm{L}$, HB $101 \mathrm{~g} / \mathrm{L}$, urinary protein excretion $0.73 \mathrm{~g} / 24 \mathrm{~h}$ ). The patient was discharged with follow-up care.

All procedures performed in studies involving human participants were in accordance with the ethical standards of the institutional research committee and with the Helsinki Declaration (as revised in 2013). Written informed consent was obtained from the patients for publication of this case report and accompanying images. A copy of the written consent is available for review by the editorial office of this journal. 

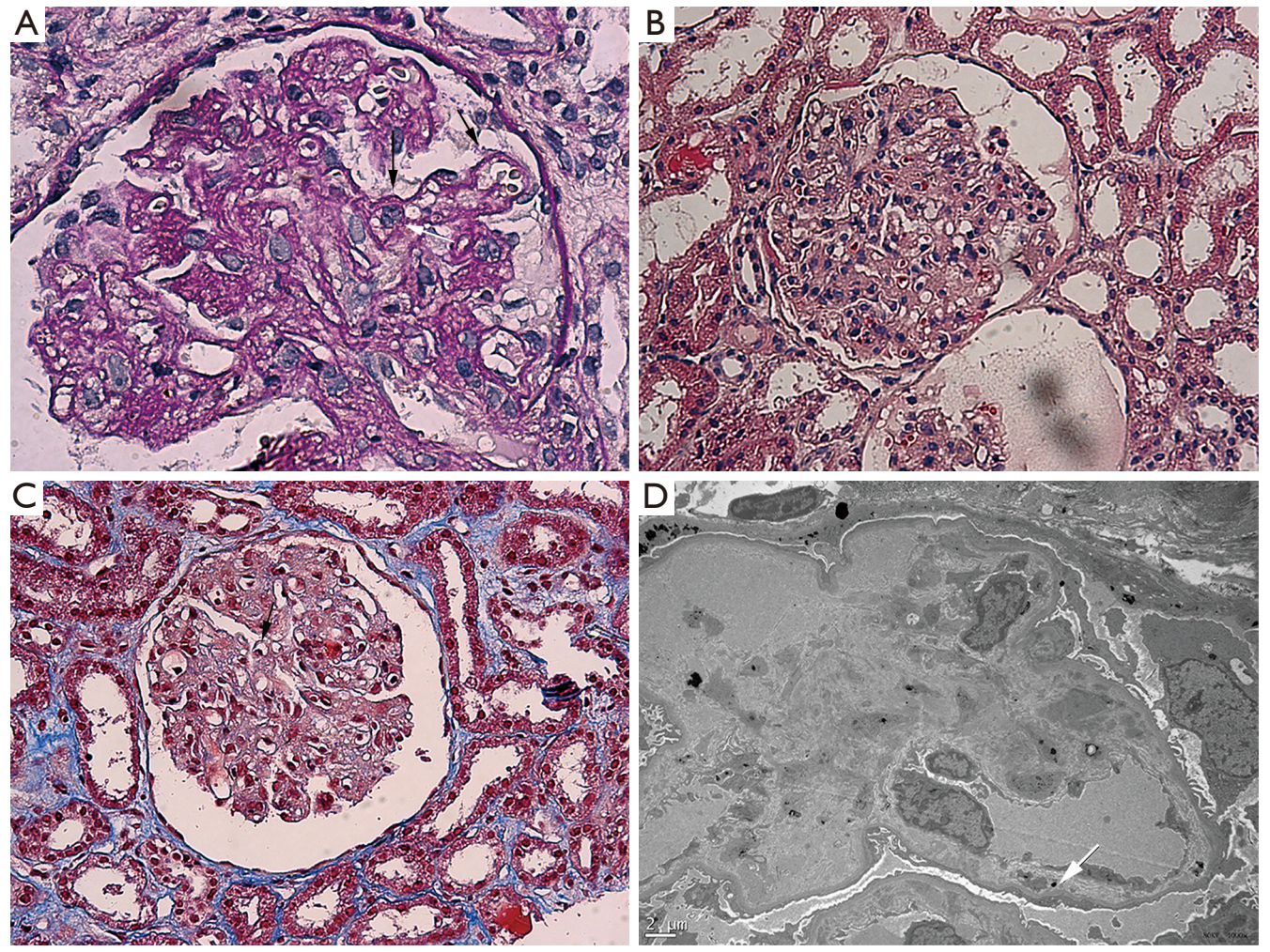

Figure 1 Pathological findings of case 1. (A-C) Light microscope showing diffuse proliferation of endothelial cells (white arrow), thickening of glomerular base membrane (GBM) with mesangial interposition and double contour of the GBM (black arrow). (A. PAS stain, original magnification 400×, B. HE stain, original magnification 200×, C. MASSON stain, original magnification 200×). (D) Electronic microscope showing thickening of inner loose layer of GBM (white arrow) and schistocytes. GBM, glomerular base membrane.

\section{Discussion}

TA-TMA can be diagnosed not only by pathological changes but also by clinical manifestations. However, there hasn't been a consensus on the diagnostic criteria of TA-TMA yet. Up to 28 different diagnostic criteria have been used in 35 different clinical researches among which the three criteria proposed by CTN (Blood and Marrow Transplant Clinical Trials Network), IWG (European Leukemia Net International Working Group) and Cho et al. (4) were most widely accepted. But these criteria all have their limitations and didn't include the newest understanding of the mechanism of TA-TMA. In 2015, some researchers (5) came up with the latest criterion in which serum C5b-9 levels was introduced and proteinuria and hypertension were used as markers of renal dysfunction. Moreover, it was confirmed that pathological criteria could be used for diagnosing TATMA. Both our reported cases met the CTN criterion and were biopsy-proven. Focusing on early detection of TATMA, some researchers (6) emphasized that a TA-TMA "triad" of hypertension, thrombocytopenia, and elevated lactate dehydrogenase (LDH) should be considered as a hallmark of TA-TMA for further investigation. TMA remains a potential complication of HSCT due to multiple risk factors including conditioning therapy, immunosuppressive regimens, GVHD, viral infection. The two patients in our cases here all underwent autologous HSCT and there was no obvious infection before TMA was diagnosed. This made it hard to attribute the pathogeny of TMA to infection, calcineurin inhibitors, and GVHD. Therefore, the aggressive conditioning therapy may act as the trigger for the TA-TMA. One study (7) reviewed the incidence of TA-TMA in 287 HSCT patients who received with high-dose $(n=111)$ or nonmyeloablative conditioning $(\mathrm{n}=176)$, the results of Cox proportional risk regression analysis showed that the use of nonmyeloablative conditioning was related to a 
Table 2 Case 2 patients' lab test parameters

\begin{tabular}{|c|c|c|c|c|c|c|c|c|c|c|c|c|c|c|}
\hline Test & $\begin{array}{l}2019 / \\
04 / 27\end{array}$ & $\begin{array}{l}2019 / \\
05 / 02\end{array}$ & $\begin{array}{l}2019 / \\
05 / 05\end{array}$ & $\begin{array}{l}2019 / \\
05 / 16\end{array}$ & $\begin{array}{l}2019 / \\
05 / 24\end{array}$ & $\begin{array}{l}2019 / \\
05 / 27\end{array}$ & $\begin{array}{l}2019 / \\
05 / 28\end{array}$ & $\begin{array}{l}2019 / \\
06 / 10\end{array}$ & $\begin{array}{l}2019 / \\
07 / 11\end{array}$ & $\begin{array}{l}2019 / \\
07 / 19\end{array}$ & $\begin{array}{l}2019 / \\
07 / 28\end{array}$ & $\begin{array}{l}2019 / \\
08 / 01\end{array}$ & $\begin{array}{l}2019 / \\
08 / 16\end{array}$ & $\begin{array}{l}2019 / \\
10 / 22\end{array}$ \\
\hline LDH (IU/L) & 357 & & & & 319 & & & & 210 & & 248 & & 262 & 241 \\
\hline Platelet counts $\left(10^{9} / \mathrm{L}\right)$ & 100 & 69 & 100 & & 106 & 125 & 139 & & 166 & 143 & 204 & 178 & 113 & 170 \\
\hline creatinine ( $\mu \mathrm{mol} / \mathrm{L})$ & 53 & & 63 & & 80 & 94 & 103 & & 158 & 160 & 156 & 152 & 119 & 117 \\
\hline \multicolumn{15}{|l|}{ C3 (normal) } \\
\hline \multicolumn{15}{|l|}{ C4 (normal) } \\
\hline \multicolumn{15}{|l|}{$\begin{array}{l}\text { Renal biopsy pathology } \\
\text { (TMA changes) }\end{array}$} \\
\hline \multicolumn{15}{|l|}{ ANA (negative) } \\
\hline \multicolumn{15}{|l|}{ dsDNA (negative) } \\
\hline \multicolumn{15}{|l|}{ Anti-Sm (negative) } \\
\hline \multicolumn{15}{|l|}{ Coombs (negative) test } \\
\hline \multicolumn{15}{|l|}{$\begin{array}{l}\text { Adamts } 13 \text { activity } \\
\text { (negative) }\end{array}$} \\
\hline \multicolumn{15}{|l|}{$\begin{array}{l}\text { Anti-factor } \mathrm{H} \text { antibody } \\
\text { (negative) }\end{array}$} \\
\hline \multicolumn{15}{|l|}{$\begin{array}{l}\text { Peripheral smear } \\
\text { (schistocytes) ( } \geq 2 / \mathrm{HPF} \text { ) }\end{array}$} \\
\hline Prednisone treatment & & & & & & & & & & & $15 \mathrm{mg}$ qd & & & $12.5 \mathrm{mg} \mathrm{qd}$ \\
\hline
\end{tabular}

LDH, lactate dehydrogenase; TMA, thrombotic microangiopathy; ANA, anti-nuclear antibodies; ANCA, anti-neutrophil cytoplastic antibodies.

lower incidence of TA-TMA (P=0.01). Another study (3) analyzed 60 pediatric recipients who underwent aHCT using different high-dose chemotherapy, 13 patients in total developed TA-TMA. Specifically, 12 of them received carboplatin/etoposide/melphalan (CEM), and 1 received cyclophosphamide/thiotepa. In comparison, both patients in our cases received myeloablative conditioning regimen of BEAC, which was suspected as the cause of TA-TMA.

It has been reported that TA-TMA typically occurs within the first 3 months after alloHSCT $(8,9)$. Whereas pediatric patients underwent an autologous HSCT may develop TA-TMA even at a median of 18 days after HSCT (3) which is quite earlier than that in our cases. Treatment of TA-TMA is based on supportive care and disease-targeted management. Withdrawing or minimizing potential triggering agents and treating co-existing conditions (e.g., hypertension) are used as first-line supportive therapy of TA-TMA. Hypertension post transplantation is considered as a putative clinical manifestation of TA-TMA $(10,11)$, and combined anti-hypertensive therapies are often 


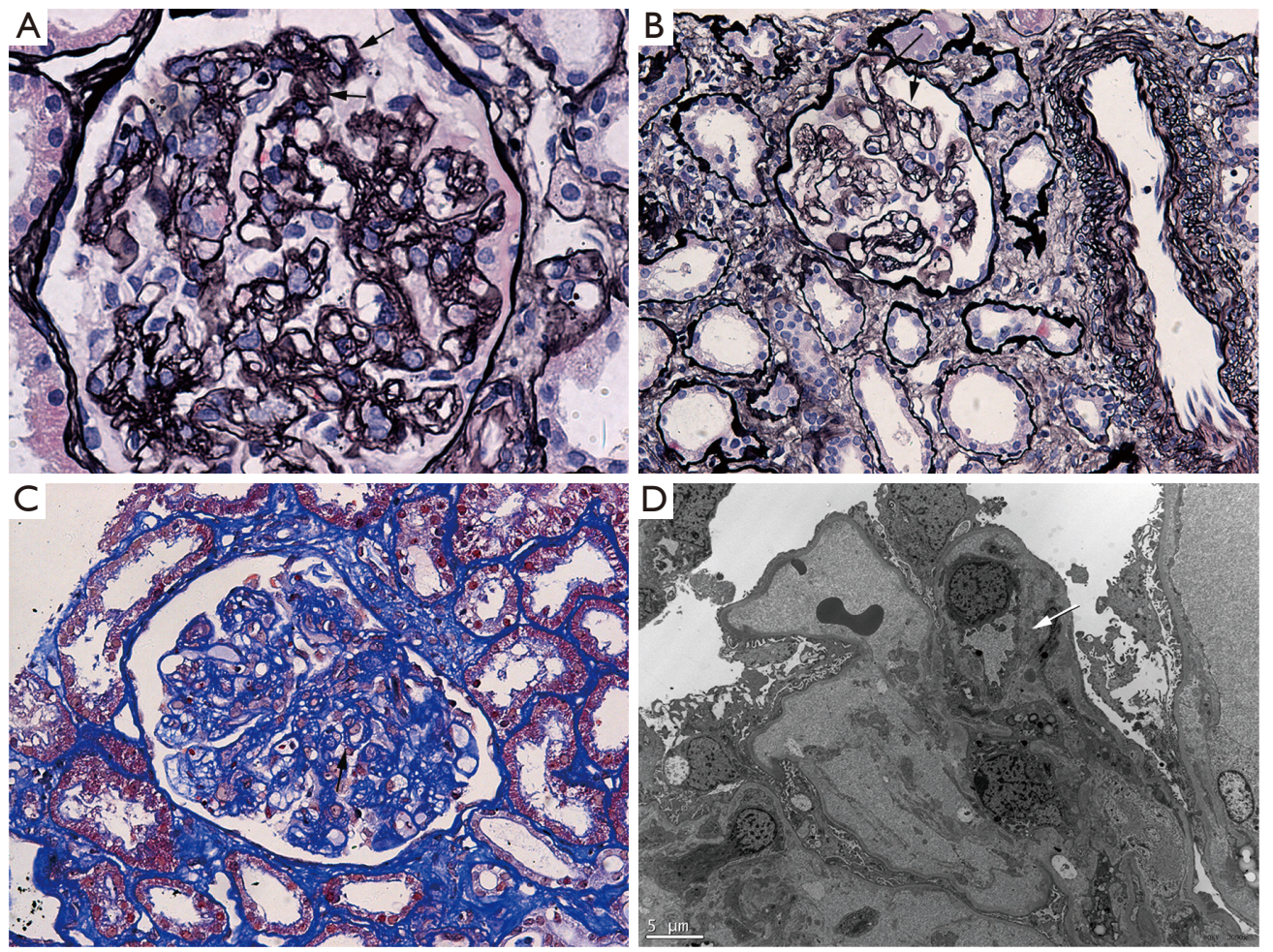

Figure 2 Pathological findings of case 2. (A-C) Light microscope showing diffuse proliferation of endothelial cells, thickening of inner aspect of GBM and double contour of the GBM (black arrow). (A. PASM stain, original magnification 400×, B. PASM stain, original magnification 200×, C. MASSON stain, original magnification 200×). (D) Electronic microscope showing thickening of inner loose layer of GBM (white arrow) and swelling of endothelial cells. GBM, glomerular base membrane.

needed to enhance efficacy (5). Some even argued in their research that all patients who were diagnosed with TATMA after aHSCT with severe hypertension need 3-6 antihypertensive medications or even medication infusions (3). However, in our cases, single antihypertensive therapy achieved adequate blood pressure control. Besides, because of the important role of complement activation in the mechanism of TA-TMA, complement blockade with eculizumab is considered as the most promising targeted therapy to date for TA-TMA. It's important to note that eculizumab for TA-TMA typically requires a longer induction time with at least 4-6 weeks of therapy. Although therapeutic plasma exchange (PTE) is not encouraged due to the controversial benefits and severe complications, for patients who present Factor $\mathrm{H}$ autoantibodies or who can be treated with PTE within 2-3 weeks of TA-TMA diagnosis, PTE could still be considered. Patients with TA-TMA are often considered to have poor prognosis such as ESRD which needs dialysis and death. Age are over 18 , significant proteinuria and elevated serum creatinine have been suggested to be poor prognostic indicators (12). It is also noted that patients who did not receive complement targeting therapy for post-aHSCT TMA are at high risk of poor treatment outcomes (13). Our cases differ from prior researches because our patients had proteinuria as an early sign of TMA with both of their urinary protein excretion decreasing rapidly to less than $1 \mathrm{~g} / 24 \mathrm{~h}$ and their platelet levels normalizing without any first-line TA-TMA targeted therapy. Furthermore, low-dose prednisone (15 $\mathrm{mg}$ once daily) was given to the two patients and their elevated serum creatinine dropped dramatically which was unusual for TMA. The epilepsy in Case 2, a common neurological complication of TMA, was resolved by anti-epileptic drugs without further specific TMA management, which confirmed the early findings of symptomatic epilepsy.

There are some limitations for this case report. Firstly, we could not conduct more in-depth analyses such as sC5b-9 level due to the restriction of our laboratory conditions. Secondly, we were not able to obtain written results of 
follow-up assessments or provide face-to-face consultation for neither of our patients, as they have been lost to followup after discharge due to residing interstate. Information was gathered through phone surveys.

\section{Conclusions}

Our study presented here indicated the occurrence of TA-TMA in adult aHSCT recipients with non-specific manifestations. Low-dose prednisone therapy may be effective to treat mild TA-TMA. We would like to alert clinicians during assessment process to increase awareness of TA-TMA when kidney injury is found to patients who underwent aHSCT.

\section{Acknowledgments}

We would like to thank Ms. Xiang Guo from Royal Adelaide Hospital for her great help in polishing our paper. We thank Dr. Yixian Guo and Dr. Guoxiang Wang from Department of Hematology of Xuanwu Hospital Capital Medical University for their help in assessing the patients' condition. We thank Dr. Linpei Jia for the constructive recommendations on literature searching.

Funding: This study is supported by Xuanwu Hospital Huizhi talent leader training program to Prof. Aihua Zhang.

\section{Footnote}

Reporting Checklist: The authors have completed the CARE reporting checklist. Available at https://apm.amegroups. com/article/view/10.21037/apm-21-226/rc

Conflicts of Interest: All authors have completed the ICMJE uniform disclosure form (available at https://apm. amegroups.com/article/view/10.21037/apm-21-226/coif). The authors have no conflicts of interest to declare.

Ethical Statement: The authors are accountable for all aspects of the work in ensuring that questions related to the accuracy or integrity of any part of the work are appropriately investigated and resolved. All procedures performed in studies involving human participants were in accordance with the ethical standards of the institutional research committee and with the Helsinki Declaration (as revised in 2013). Written informed consent was obtained from the patients for publication of this case report and accompanying images. A copy of the written consent is available for review by the editorial office of this journal.

Open Access Statement: This is an Open Access article distributed in accordance with the Creative Commons Attribution-NonCommercial-NoDerivs 4.0 International License (CC BY-NC-ND 4.0), which permits the noncommercial replication and distribution of the article with the strict proviso that no changes or edits are made and the original work is properly cited (including links to both the formal publication through the relevant DOI and the license). See: https://creativecommons.org/licenses/by-nc-nd/4.0/.

\section{References}

1. Gavriilaki E, Sakellari I, Anagnostopoulos A, et al. Transplant-associated thrombotic microangiopathy: opening Pandora's box. Bone Marrow Transplant 2017;52:1355-60.

2. Tolbert VP, Dvorak CC, Golden C, et al. Risk Factors for Transplant-Associated Thrombotic Microangiopathy after Autologous Hematopoietic Cell Transplant in HighRisk Neuroblastoma. Biol Blood Marrow Transplant 2019;25:2031-9.

3. Jodele S, Dandoy CE, Myers K, et al. High-dose Carboplatin/Etoposide/Melphalan increases risk of thrombotic microangiopathy and organ injury after autologous stem cell transplantation in patients with neuroblastoma. Bone Marrow Transplant 2018;53:1311-8.

4. Cho BS, Yahng SA, Lee SE, et al. Validation of recently proposed consensus criteria for thrombotic microangiopathy after allogeneic hematopoietic stem-cell transplantation. Transplantation 2010;90:918-26.

5. Jodele S, Laskin BL, Dandoy CE, et al. A new paradigm: Diagnosis and management of HSCT-associated thrombotic microangiopathy as multi-system endothelial injury. Blood Rev 2015;29:191-204.

6. Dvorak CC, Higham C, Shimano KA. TransplantAssociated Thrombotic Microangiopathy in Pediatric Hematopoietic Cell Transplant Recipients: A Practical Approach to Diagnosis and Management. Front Pediatr 2019;7:133.

7. Willems E, Baron F, Seidel L, et al. Comparison of thrombotic microangiopathy after allogeneic hematopoietic cell transplantation with high-dose or nonmyeloablative conditioning. Bone Marrow Transplant 2010;45:689-93.

8. George JN, Selby GB. Thrombotic microangiopathy after allogeneic bone marrow transplantation: a pathologic 
abnormality associated with diverse clinical syndromes.

Bone Marrow Transplant 2004;33:1073-4.

9. Daly AS, Hasegawa WS, Lipton JH, et al. Transplantationassociated thrombotic microangiopathy is associated with transplantation from unrelated donors, acute graft-versushost disease and venoocclusive disease of the liver. Transfus Apher Sci 2002;27:3-12.

10. Jodele S, Davies SM, Lane A, et al. Diagnostic and risk criteria for HSCT-associated thrombotic microangiopathy: a study in children and young adults. Blood 2014;124:645-53.

11. Laskin BL, Goebel J, Davies SM, et al. Small vessels, big trouble in the kidneys and beyond: hematopoietic stem cell transplantation-associated thrombotic microangiopathy. Blood 2011;118:1452-62.

12. Khosla J, Yeh AC, Spitzer TR, et al. Hematopoietic stem cell transplant-associated thrombotic microangiopathy: current paradigm and novel therapies. Bone Marrow Transplant 2018;53:129-37.

13. Schoettler M, Lehmann L, Li A, et al. Thrombotic Microangiopathy Following Pediatric Autologous Hematopoietic Cell Transplantation: A Report of Significant End-Organ Dysfunction in EculizumabTreated Survivors. Biol Blood Marrow Transplant 2019;25:e163-8.
Cite this article as: Dong X, Jia Q, Fu W, Li Y, Lin N, Li W, Ye W, Wen Y, Zhang A. Two unusual cases of autologous HSCT related TMA with kidney injury. Ann Palliat Med 2022;11(4):1546-1553. doi: 10.21037/apm-21-226 